\title{
EVALUATION OF LEVELLING DATA FOR USE IN VERTICAL CRUSTAL MOVEMENTS MODEL IN POLAND
}

\author{
Kamil KOWALCZYK ${ }^{1}{ }^{*}$ and Jacek RAPINSKI ${ }^{2)}$ \\ 1) Department of Land Surveying and Geomatics, University of Warmia and Mazury in Olsztyn, Poland \\ 2) Institute of Geodesy, University of Warmia and Mazury in Olsztyn, Poland \\ *Corresponding author's e-mail: kamil.kowalczyk@uwm.edu.pl
}

(Received February 2013, accepted April 2013)

\begin{abstract}
The development of an elevation frame requires a movement model of the Earth's crust. Currently, regardless of the existence of ASG-EUPOS, it seems that the most reasonable approach is to use the model developed from the levelling data. In Poland three maps of vertical crustal movements were developed on the basis of levelling data. The most recent version was published in 2006. In the above mentioned elaborations, the vertical crustal movements were calculated from two subsequent first order levelling campaigns. The results of all four levelling campaigns in Poland were accumulated and digitalized to include more data. The colocation method was used to develop the model. The graphical representation was made with triangulation and linear interpolation. One unified database was developed on the basis of collected and unified data set of unadjusted observations. The first trials of common use of the three first order levelling campaigns were performed in 2008. However the available levelling data was not complete. The goal of this paper is to evaluate the usefulness of the data from the last three campaigns of precise levelling for the development of vertical movement model in Poland.
\end{abstract}

KEYWORDS: vertical crustal movements, kinematic height frame

\section{INTRODUCTION}

In Europe, the work to harmonize the height network (ULEN) and European Reference System definition of height (EVRS) (Sacher et al., 2008) is under way. It began in 1994, with 3.0 resolution adopted at the EUREF symposium in Warsaw. The network is called UELN-95. In 1998, following the addition of some data from Eastern Europe, the UELN-95/98 network was established and its development was completed in the same year. In 2000 the EUREF Symposium in Tromso adopted the first definition of EVRS and created the European system called EVRF2000 implemented on the basis of UELN-95/98. The continued efforts to modernize and upgrade the height network in European countries as well as the obsolescence of measurements due to the minimum vertical crustal movements in 2005, led to further developments. Resolution No. 3 adopted at the EUREF Symposium in Vienna recognized the need to implement the new version of EVRS. Thus, the developed EVRF2007 was implemented through 13 points evenly distributed throughout Europe taking the stability condition of the points into account. Data from 14 countries, including Poland, were used to develop EVRF2007. The measurements were reduced to a common epoch 2000 using the NKG (Nordic Geodetic Commission) model of vertical movements (Agren and Svensson, 2007). In 2008, at a symposium in Brussels, EVRF2007 was recommended as the reference system for geoinformation. The detailed description of the development of EVRF2007 can be found in the work of Sacher et al. (2008).

In Poland, in 2012, the Regulation of the Council of Ministers from October $15^{\text {th }} 2012$ on national spatial reference system introduced the PLEVR2007-NH system of heights, which is a mathematical and physical implementation of the European Earth height system EVRS. We are currently working on the development of the concept of this system.

According to the Head Office of Geodesy and Cartography the following corrections must be included in the development of the concept of height system:

- normal correction, lunisolar correction, thermal correction, correction of levelling rods,

- correction due to the vertical crustal movements,

- transition to zero flow quasi-geoid.

In Poland, three maps of vertical crustal movements were developed. One of them served as a basis for the development of the numerical model "vcm 2006" (Kowalczyk, 2005; 2006a, b, c), where the nodes of vertical movement were interpolated including changes in the level of the Baltic Sea with least squares Hirvonen collocation function (Kowalczyk, 2006b). The graphical representation was made with triangulation and linear interpolation (Kowalczyk et al., 2010). 


\section{Campaign \#1 1926-1937}

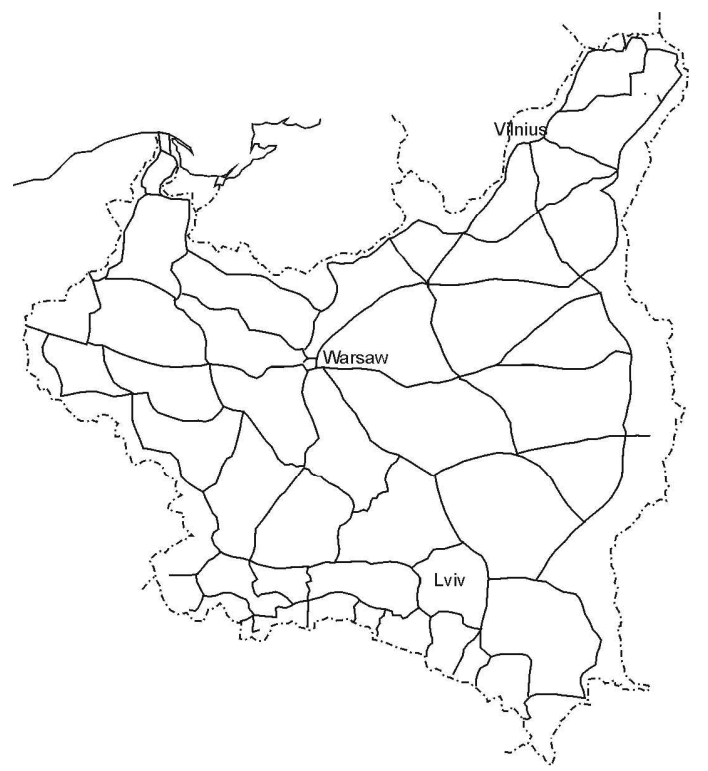

Campaign \#3 1974-1982

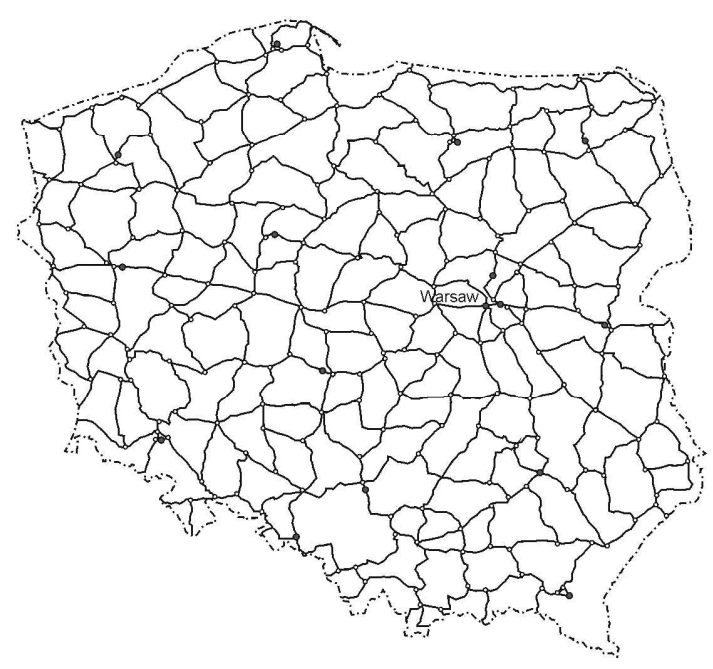

Campaign \#2 1953-1955

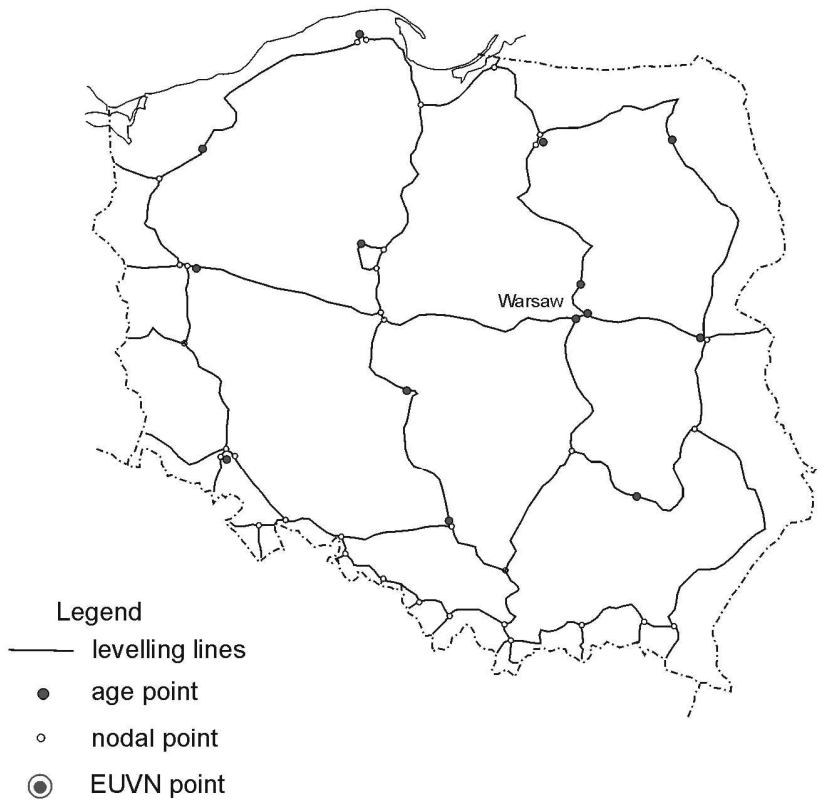

Campaign \#4 1997-2003

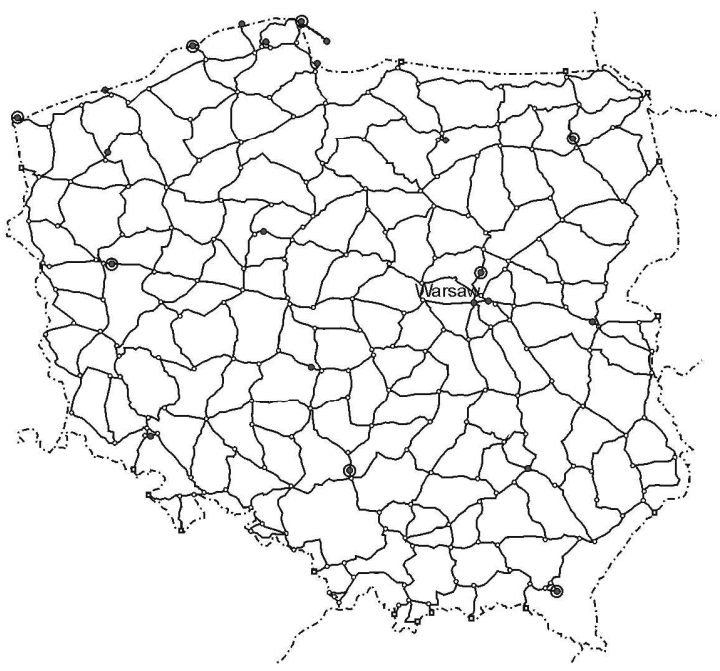

Fig. 1 Levelling campaign in Poland (Kowalczyk, 2006c).

Unadjusted height differences on levelling lines from two levelling campaigns (1974-1982 and 19972003, Figure 1) were used as input data.

Since the last development of the "vcm2006" model we have managed to gather and process to digital data the first-class levelling data from the years 1926-1937 and 1953-1955, Figure 1 (Kowalczyk et al., 2011). The first class levelling database content is presented in Table 1.

In the first stage a quantitative assessment of the gathered levelling data was performed along with the identification of common points in all four levelling campaigns. In the second stage the vertical movements on the lines of levelling were calculated. In the third step the resulting vertical movements were adjusted in three variants. Thus, the obtained corrections to the vertical movements were evaluated statistically.

The collected levelling data set can be used to develop a new model of vertical crustal movements or to reinforce a model of vertical crustal movements, which is necessary in the kinematic height frame of Poland. Therefore, the aim of this publication is to investigate the suitability of levelling data from three campaigns to build a model of vertical movements in the future quasi-kinematic height network.

\section{IDENTIFICATION AND QUANTIFICATION OF THE GATHERED LEVELLING MATERIAL}

First, the quantitative data is summarized for each precise levelling campaign together with the resulting mean error after adjustment (Table 2). 
Table 1 Content of the catalogues and survey logs.

\begin{tabular}{|c|c|c|c|c|}
\hline & 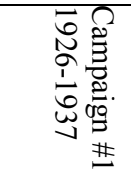 & 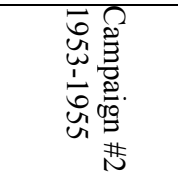 & 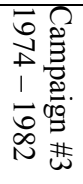 & 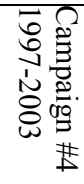 \\
\hline e normal corrections available & No & Yes & Yes & Yes \\
\hline line numbering available & Yes & Yes & Yes & No \\
\hline benchmark number available & No & Yes & Yes & Yes \\
\hline benchmark type available & Yes & Yes & Yes & Yes \\
\hline section length available & Yes & Yes & No & No \\
\hline change available & No & Yes & Yes & Yes \\
\hline head number available & No & Yes & Yes & Yes \\
\hline benchmark height available & Yes & Yes & Yes & Yes \\
\hline location at the points described & Yes & Yes & Yes & Yes \\
\hline e the horizontal coordinates at points available & No & Sporadically & Yes & Yes \\
\hline e adjusted height difference available & No & Yes & Yes & Yes \\
\hline e unadjusted height difference plus levelling rod corrections available & No & Yes & Yes & Yes \\
\hline additional head attribute available & No & Yes & Yes & Yes \\
\hline measurement date available & Yes & Yes & Yes & Yes \\
\hline benchmark ID available & No & No & No & Yes \\
\hline line ID available & No & No & No & Yes \\
\hline stabilization code available & No & No & Yes & Yes \\
\hline e benchmark groups available & No & No & Yes & Yes \\
\hline
\end{tabular}

Table 2 Geometric specifications of the networks in Poland.

\begin{tabular}{|c|c|c|c|c|c|c|c|c|}
\hline \multirow{2}{*}{ Campaign } & \multirow{2}{*}{$\begin{array}{l}\text { Line } \\
\text { length } \\
{[\mathrm{km}]}\end{array}$} & \multicolumn{3}{|c|}{ Number } & \multicolumn{3}{|c|}{ Mean length $[\mathrm{km}]$} & \multirow{2}{*}{$\begin{array}{l}\text { Mean error } \\
\text { after } \\
\text { adjustment } \\
{[\mathrm{mm}]}\end{array}$} \\
\hline & & 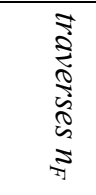 & 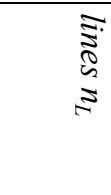 & 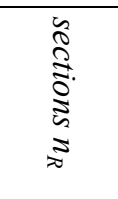 & 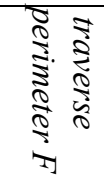 & 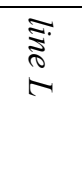 & 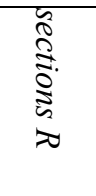 & \\
\hline 1926-1937 & 10046 & 36 & 121 & 5907 & 445 & 83 & 1.7 & \pm 1.04 \\
\hline 1953-1955 & 5778 & 12 & 60 & $\begin{array}{l}\text { about } \\
4500\end{array}$ & 609 & 96 & 1.3 & \pm 0.78 \\
\hline 1974-1982 & 17015 & 135 & 371 & 15827 & 221 & 46 & 1.1 & \pm 0.84 \\
\hline $1997-2003$ & 17516 & 138 & 382 & 16150 & 217 & 45.8 & 1.085 & \pm 0.88 \\
\hline
\end{tabular}

The analysis of Table 2 may lead to the conclusion that all the data constitute a significant contribution to the achievement of the objective of this article. However, looking at Figure 1, the levelling line from the 1926 to 1937 (\#1) campaign does not coincide fully with the lines of other campaigns. Therefore, the initial identification of common points with all four campaigns precise levelling was performed.
The most comprehensive material to determine the vertical movement of the Earth's crust represent data from the levelling campaigns in the years 19741982 (\#3) and 1997-2003 (\#4). These allowed to distinguish as many as 235 common nodal benchmarks and 11000 indirect common benchmarks. The campaigns in the years 1953-1955 (\#2) and 1974-1982 distinguished 43 common nodal benchmarks and about 2600 indirect common 


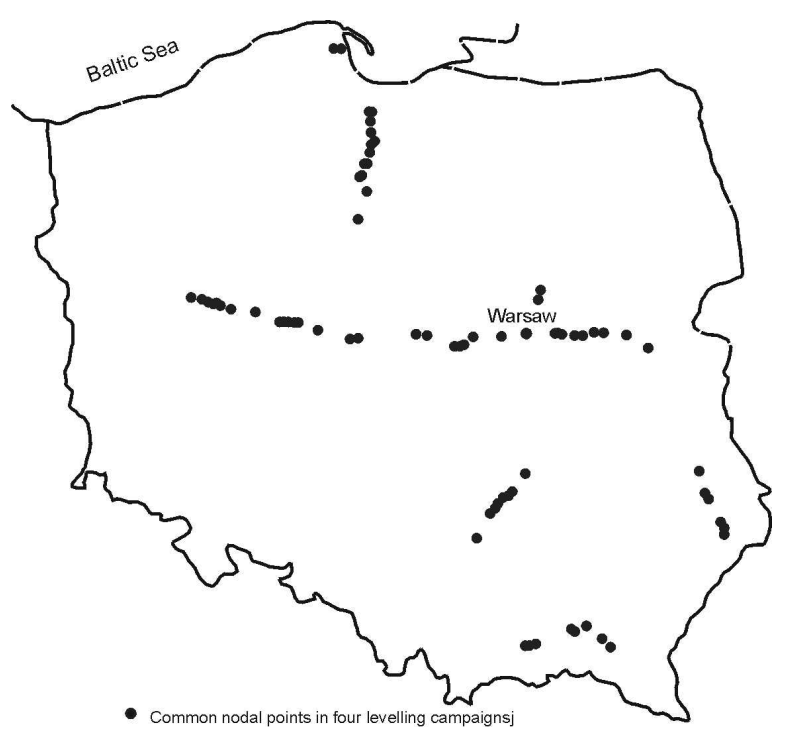

Fig. 2 Common nodal points from campaigns \#1, $\# 2, \# 3, \# 4$.

benchmarks. Only 137 common benchmarks were distinguished from the 1926-1937 and 1953-1955 campaigns. The comparison of all four campaigns shows that one cannot use the available levelling data from the years 1926-1937 to determine the vertical movement, mainly due to the small number of common benchmarks (78 benchmarks common) Figure 2, and the distribution of these benchmarks, which makes it impossible to determine the proper vertical movements. For further analysis, it was decided to use the data from the years 1953-1955, 1974-1982, and 1997-2003.

\section{CALCULATION OF THE VERTICAL CRUSTAL MOVEMENTS FOR THE LEVELLING LINES}

After a preliminary analysis of the levelling material the data was prepared to adjustment. In this step, the main focus was on preparation of the levelling data in order to calculate the vertical movements on lines of double levelling. In this stage unadjusted movements on each line of double levelling were calculated, which consisted of: calculation of height differences between common benchmarks in subsequent campaigns, and calculation time differences between measurements. In addition, the mean errors of vertical movements on each line were calculated (in ppm).

While the levelling material from the 1974-1982 and 1997-2003 campaigns did not require too many modifications (early development), the material from the 1953-1955 campaign had to be prepared according to the previously adopted standards.

To increase the usefulness of these data, additional 44 common benchmarks between the 19531955 and 1974-1982 campaigns were identified. Densification or reduction at model points concentration was made as shown in Figure 3.

As a result, the material of the three precise levelling campaigns in Poland, forming double levelling lines (Table 3) was used for the adjustment. The adjustment was performed in three scenarios:

- vertical crustal movements between campaigns two and three,

- vertical crustal movements between campaigns three and four,

- common adjustment of campaigns two, three, and four.

In each scenario, raw, unadjusted height differences were used to calculate the vertical movements. They were then adjusted using the least squares method to obtain the vertical crustal movements network. Each observation used in the adjustment was calculated using the following formula:

$$
v_{i}=\frac{\Delta h_{i j}}{\Delta T_{i j}}
$$

where: $v_{i}-$ vertical movement of the line, $h_{i}, h_{j}-$ height difference in epoch $\mathrm{i}$ and $\mathrm{j}, \Delta \mathrm{T}$ - difference between epochs $\mathrm{i}$ and $\mathrm{j}$ expressed in decimal years, $\Delta \mathrm{h}_{\mathrm{ij}}=\mathrm{h}_{\mathrm{i}}-\mathrm{h}_{\mathrm{j}}$

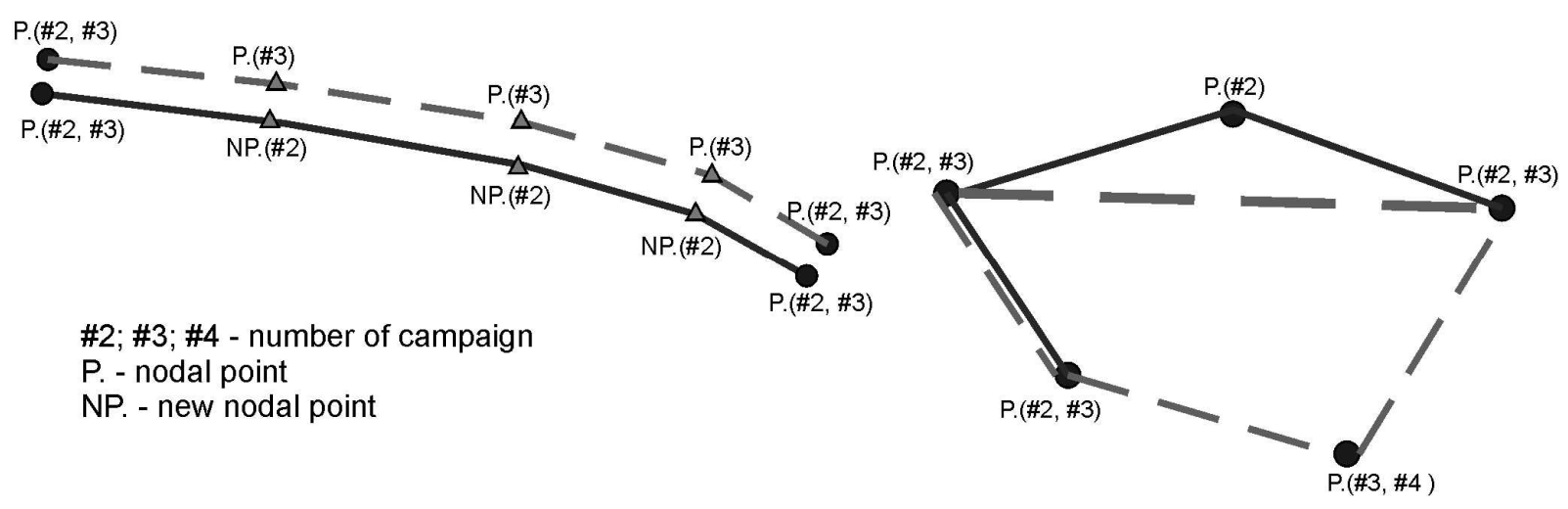

Fig. 3 Strengthening the levelling material in the 1953-1955 campaign. 
Table 3 Content of the catalogues and survey logs.

\begin{tabular}{lcc}
\hline $\begin{array}{l}\text { Vertical crustal movements between } \\
\text { campaigns }\end{array}$ & Number of stations & Number of observations \\
\hline $1953-1955$ and 1974-1982 & 97 & 113 \\
$1974-1982$ and 1997-2003 & 222 & 366 \\
$1953-1955$ and 1974-1982 and 1997-2003 & 227 & 479 \\
\hline
\end{tabular}

Table 4 Adjustment summary.

\begin{tabular}{|c|c|c|c|c|c|c|c|c|c|c|c|c|c|c|c|c|c|}
\hline \multirow[b]{2}{*}{ 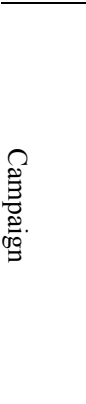 } & \multicolumn{2}{|c|}{ Iteration1 } & \multirow[b]{2}{*}{$\begin{array}{l}\bar{E} \\
0 \\
\frac{0}{0} \\
0 \\
0 \\
0 \\
0 \\
0 \\
0 \\
0\end{array}$} & \multirow[b]{2}{*}{ 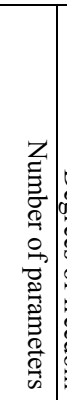 } & & \multirow[b]{2}{*}{ 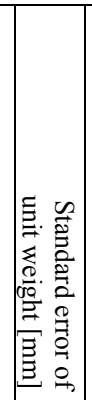 } & \multirow[b]{2}{*}{ 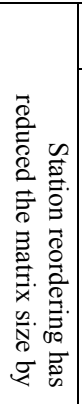 } & \multicolumn{3}{|c|}{$\begin{array}{l}\text { Classified } \\
\text { residuals }\end{array}$} & \multicolumn{7}{|c|}{ Statistics of lines } \\
\hline & 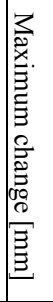 & 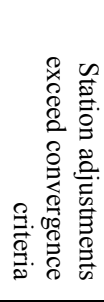 & & & & & & $\begin{array}{l}c \\
\vdots \\
0 \\
0 \\
0 \\
0 \\
0 \\
0 \\
0 \\
0\end{array}$ & 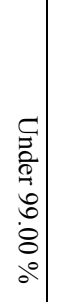 & $\begin{array}{l}0 \\
0 \\
0 \\
0 \\
0 \\
8 \\
0 \\
0\end{array}$ & 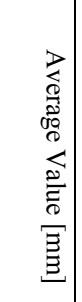 & 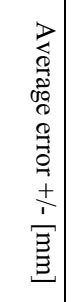 & 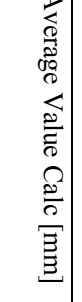 & 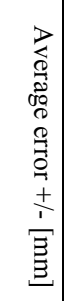 & 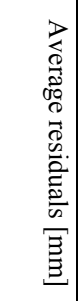 & 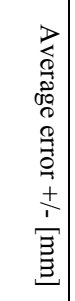 & 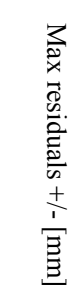 \\
\hline & 4.8 & 97 & 113 & 97 & 16 & 5.9 & $91 \%$ & 53 & 4 & 56 & -0.07 & 0.06 & -0.06 & 0.06 & -0.01 & 0.02 & -0.3 \\
\hline$\# 3 \# 4$ & 4.6 & 222 & 366 & 222 & 144 & 6.5 & $90 \%$ & 98 & 30 & 238 & -0.01 & 0.07 & -0.01 & 0.05 & 0.01 & 0.04 & 1.76 \\
\hline $2 \# 3 \# 4$ & 3.5 & 227 & 479 & 227 & 252 & 9.2 & $91 \%$ & 109 & 29 & 341 & -0.02 & 0.07 & 0.00 & 0.04 & -0.02 & 0.05 & \\
\hline
\end{tabular}

The errors used for weighting the observations were calculated with assumption that the height differences are uncorrelated:

$m_{v_{i}}=\sqrt{\frac{2 L^{2}}{\Delta T_{i j}^{2}}+\frac{\Delta h_{i j}^{2}}{\Delta T_{i j}^{2}} \cdot(0,5 \mathrm{~mm} / \text { year })^{2}}$

where: $\mathrm{L}$ - length of line in $\mathrm{km}, \mathrm{T}$ - line measurement date, $\mathrm{h}$ - unadjusted height difference of the levelling line, 0.5 - assumed maximum vertical movement error.

Prior to the adjustment, the levelling loops disclosure of double levelling networks (1953-1955 and 1974-1982 or 1974-1982 and 1982-2003) were calculated along with its mean errors (Kakkuri and Vermeer, 1985):

$$
\begin{aligned}
\varphi_{\Delta v} & =0.15 \sqrt{\sum L[\mathrm{~km}] \mathrm{mm} / \text { year }} \\
m & =\sqrt{\frac{1}{N} \sum_{i-1}^{N} \frac{\varphi^{2}}{\sum L[\mathrm{~km}]}}
\end{aligned}
$$

where: $\varphi_{\Delta v}-$ maximum loop disclosure, $\varphi$ - calculated loop disclosure, $\mathrm{N}$ - number of loops.

The loop disclosures in campaigns 1953-1955 and 1974-1982 have exceeded allowable value in one loop (obtained -8.34 , calculated -4.8 ), while in one case it was $0.04 \mathrm{~mm} /$ year near the limit. The total number of loops was 7 , the mean error was +-0.09 mm/year. In campaigns 1974-1982 and 19972003 the loops disclosures have exceeded the limit in two loops (obtained - 3.60, calculated - 2.4 and obtained - 3.11, calculated-2.18). The total number of loops was 128 , the mean error was $+-0,15 \mathrm{~mm} /$ year. The loops disclosure in 1953-1955 and 1974-1982 has smaller mean error due to a smaller number of loops and shorter levelling lines.

\section{ADJUSTMENT AND RESULT ANALYSIS}

The three vertical movement networks (velocities on the levelling lines between nodal points) were adjusted using SNAP v. 2.3.44 (Survey Network Adjustment Program) developed by Land Information New Zealand. The calculated vertical movements are the movements of the nodes, i.e. relative to the adopted one fixed point. The adjustment has been made with a fixed point in the centre of Poland so that it appeared as a nodal point in all three versions of the adjustment. The total number of observations involved in the adjustment was 479 , of which in the campaigns 1953-1955 and 1974-1982 the number was 113. The summary of the adjustment is presented in Table 4. The obtained vertical crustal movement velocities are presented in Figure 4. 

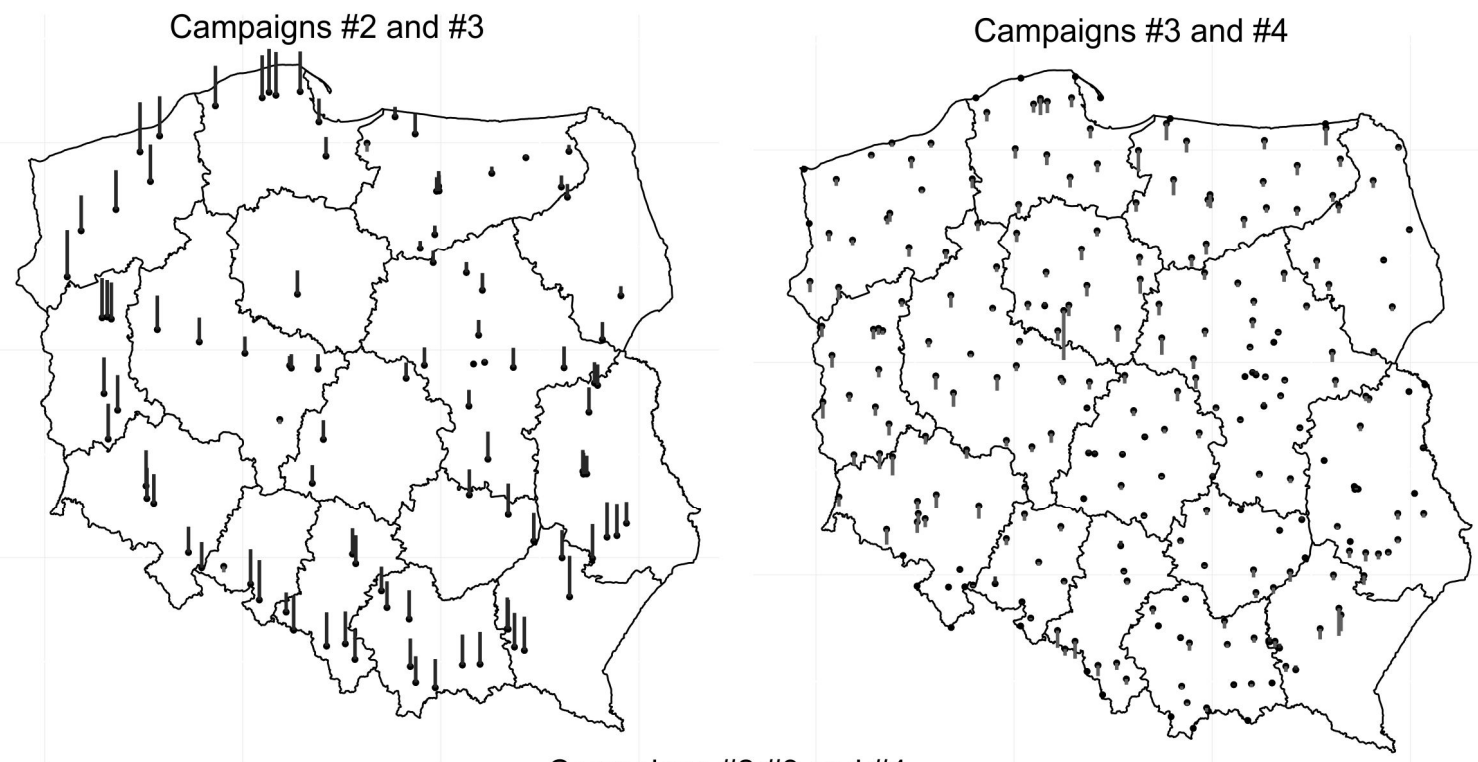

Campaigns \#2 \#3 and \#4

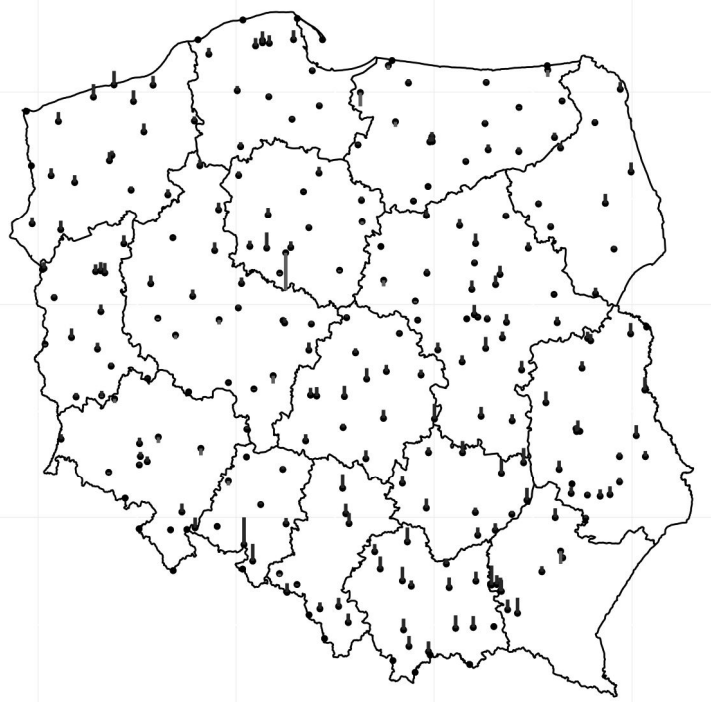

Fig. 4 Distribution at residuals at adjusted vertical crustal movements.

Based on Figure 4, it can be noticed that the direction of movement from the 1953-1955 and 19741982 campaigns is opposite to that from 1974-1982 and $1997-2003$ or $1953-2003$. It is also clear that the largest residuals on nodal points were obtained from the 1953-1955 and 1974-1982 campaigns in the western and southern parts of Poland. In the remaining two adjustments the larger residuals show occasionally in the entire network. The errors of relative vertical crustal movements are:

- 1953-1955 and 1974-1982 campaign - the mean movement error in the node was smaller than $0.17 \mathrm{~mm} /$ year

- 1974-1982 and 1997-2003 campaign - the mean movement error in the node was smaller than $0.10 \mathrm{~mm} /$ year
- $\quad 1953-1955,1974-1982$, and 1997-2003 campaign - the mean movement error in the node was smaller than $0.10 \mathrm{~mm} /$ year

Summarizing Table 4, the largest vertical movement was observed on the nodal point 32240016 calculated from the 1953-1955 and 1974-1982 campaigns $(4.8 \mathrm{~mm} / \mathrm{y})$. In the adjustments 97, 222, 227 the nodal points were adjusted with maximum of 479 observations from campaigns 1953-1955, 1974-1982, and 1977-2003. The standard error of unit weight was in the range of $5.9 \mathrm{~mm}(\# 23)$ to $9.2 \mathrm{~mm}(\# 234)$. The mean vertical movement from all campaigns on all points was from $-0.07 \mathrm{~mm} /$ year (\#23) to $-0.01-0.02$ $\mathrm{mm} /$ year (\#23 and \#234), and the average residuals from $-0.02 \mathrm{~mm} /$ year to $0.01 \mathrm{~mm} /$ year. The maximum residuum was $2.00 \mathrm{~mm} /$ year in campaign (\#234). 
Campaigns \#2 and \#3

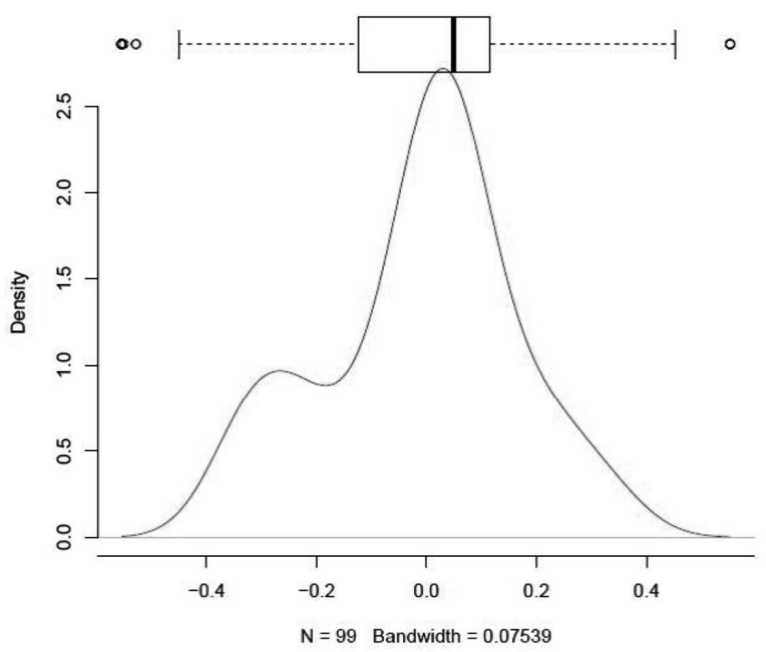

Campaigns \#3 and \#4

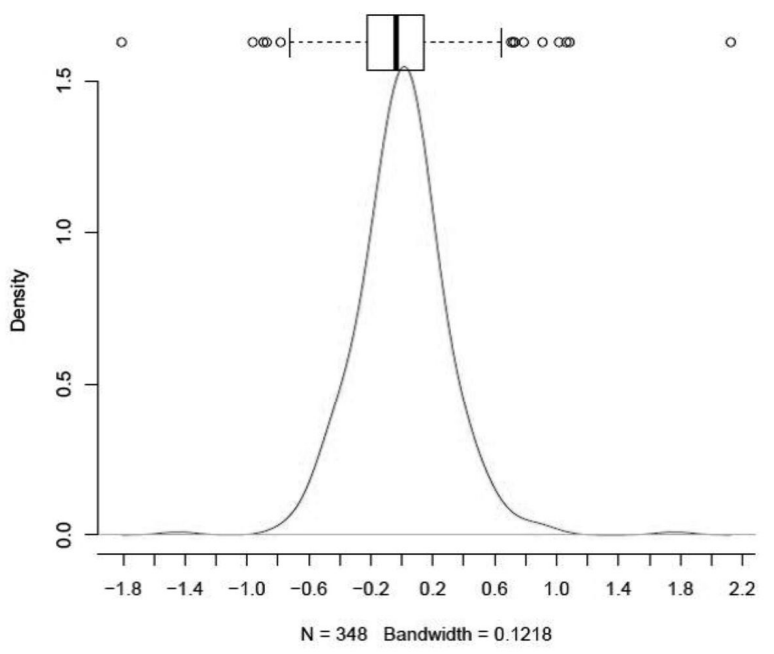

Campaigns \#2 \#3 and \#4

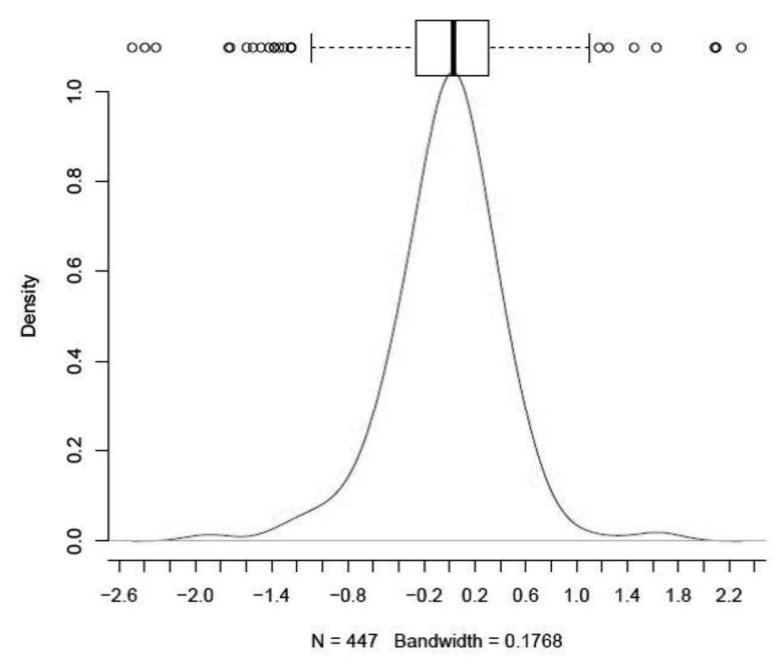

Fig. 5 Residuals distribution as a box plot along with corresponding density function.

For further analysis, only the observation residuals were used, as the main factor in assessing the relationship between successive versions of the adjustment.

The suitability analysis of the data from three precise levelling campaigns were based on the observation residuals. To complete this task the following statistical methods and graphs based on statistical methods were used: box-plots, Pearson's, Kendall's, and Sperman's correlation tests and QQ plots.

Figure 5 depicts the distributions of observation residuals as a box-plot. The box-plot (Benjamini, 1988) is a form of graphic representation of statistical distribution of features, found mostly in computer packages to support the process of analysis and interpretation of statistical data. It allows enclosing in one drawing the information on the location, dispersion and shape of the empirical distribution of the test characteristics. It is created by plotting the values of some parameters of the distribution on the horizontal axis. The rectangle placed above the axis has its left side at the first quartile of the data and right side on the third quartile. The width of the box represents interquartile range. The vertical line inside the box represents the median. The horizontal lines at the edge of the plot represent the minimum and maximum value in the data set (Benjamini, 1988).

Figure 5 shows that the residuals from the years1953-1955, 1974-1982, 1997-2003 and 1974- 

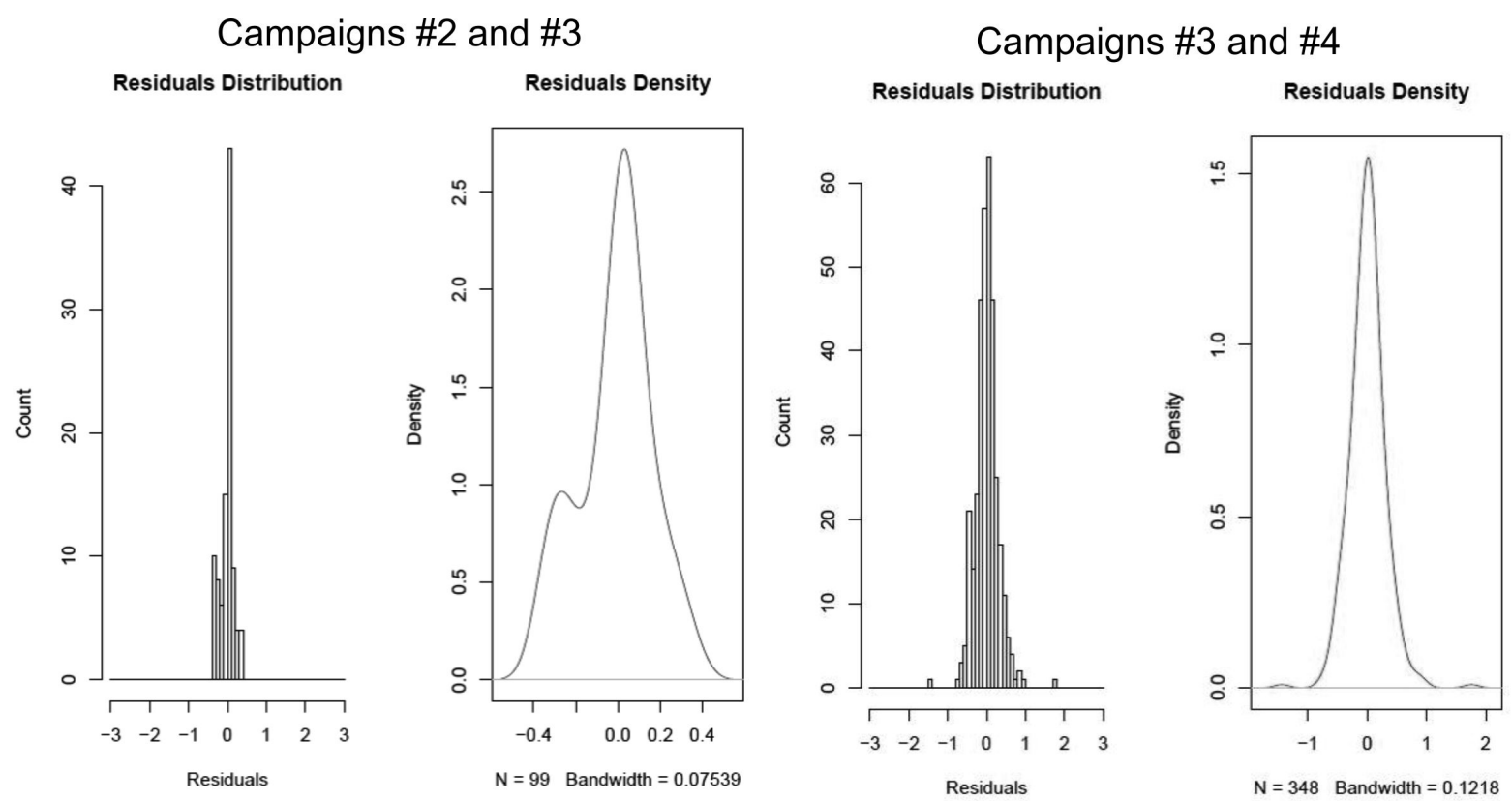

Campaigns \#2 \#3 and \#4
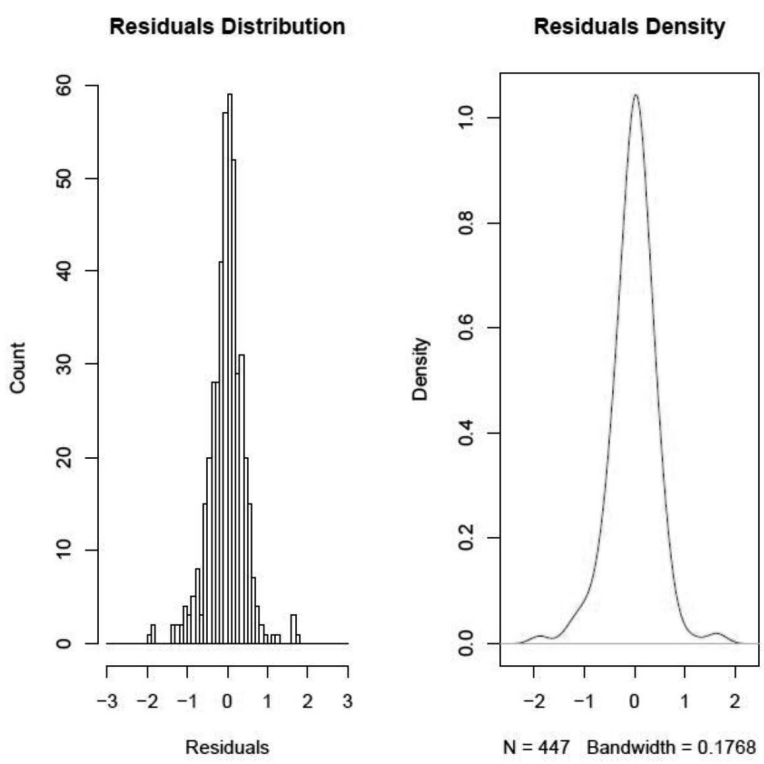

Fig. 6 Residual density distribution for vertical movements.

1982, 1997-2003 have normal distribution. Only single points do not fulfil the criterion of triple mean error. The mean error for the data 1953-1955, 1974$1982,1997-2003$ is close to one. For the 1974-1982, 1997-2003 data it equals 1.5 with slight offset to the right. In the 1953-1955, 1974-1982 version the criterion of triple mean error is not fulfilled by even smaller number of residuals, but the distribution is not normal. The mean error is about 2.5. The left skewness of the distribution is noticeable. Prepared histograms show the distributions (Figure 6).

To see if the residuals between campaigns 19531955, 1974-1982 and 1974-1982, 1997-2003 are correlated, three tests were performed - Pearson,
Kendall and Spearman correlation tests. The null hypothesis in the above tests is ,the correlation is equal to 0 " with the alternative hypothesis "the correlation is different than 0" (Hollander and Wolfe, 1973). The P-values obtained from the tests are 0.87 , 0.44 and 0.37 for Pearson, Kendall and Spearman respectively. Thus, the null hypothesis is proved. The correlation coefficient for the above residuals is about -0.02 .

The last test performed was the QQ test (Wilk and Gnanadesikan, 1968). In this test the differences between normal distribution (horizontal axis) and standardised residuals (vertical axis) are depicted. From Figure 7 it is clear that for campaigns 1953- 


\section{Campaign 1953-1955 and 1974-1982}

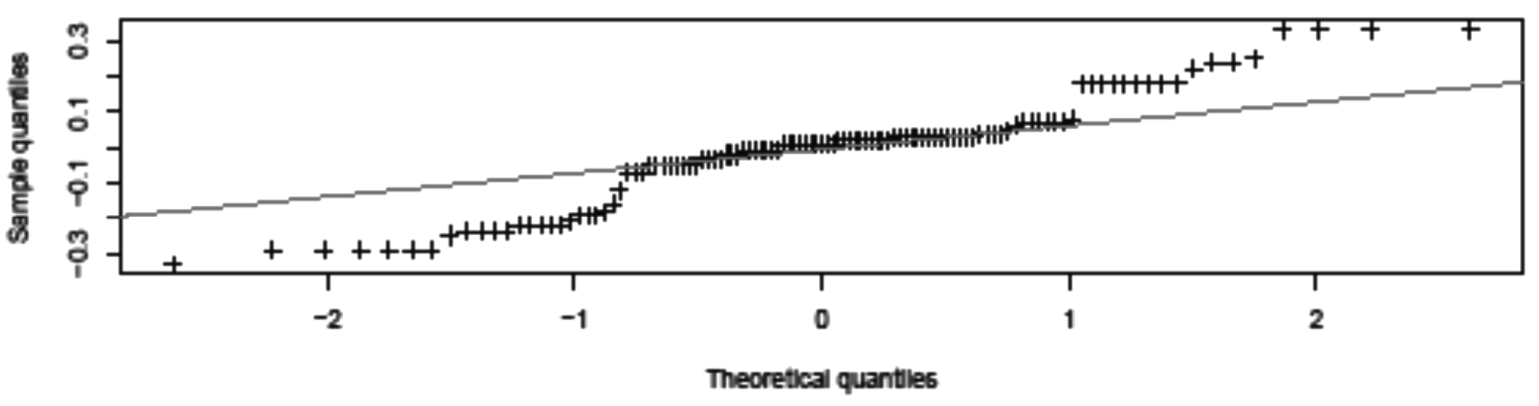

Campaign 1974-1982 and 1997-2003

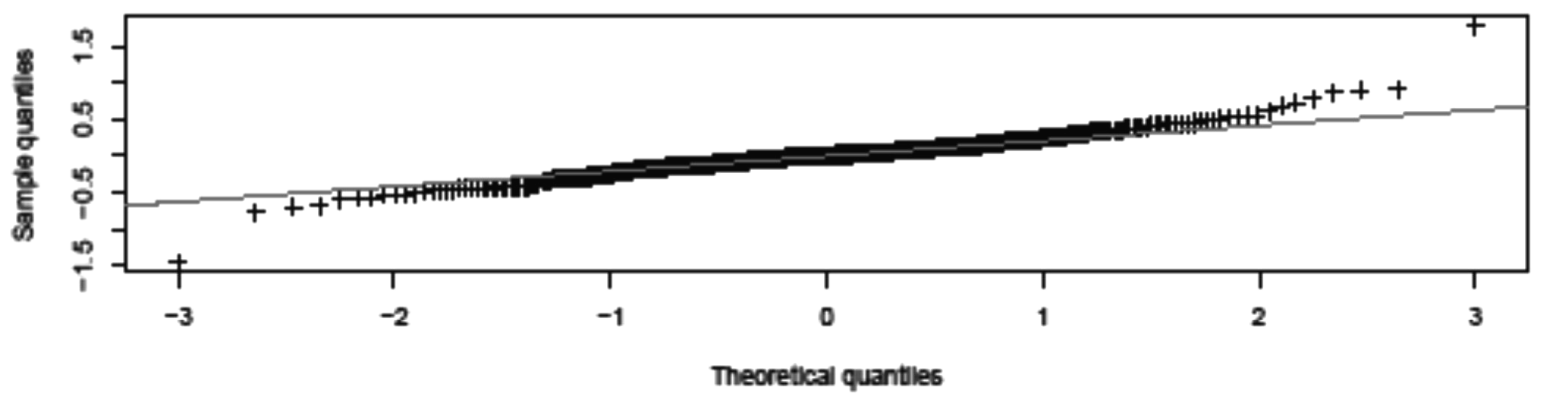

Campaign 1953-1955 and 1974-1982 and 1997-2003

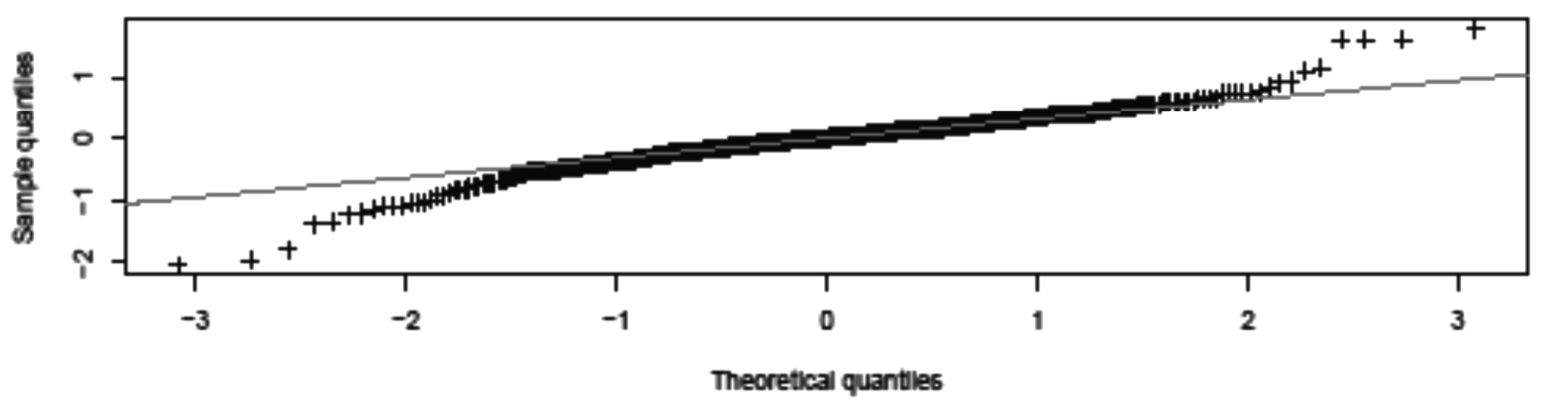

Fig. 7 Results of QQ test.

1955, 1974-1982 the distribution has much larger variance than the residuals for the 1974-1982, 19972003 campaigns.

\section{CONCLUSIONS}

The main objective of this publication was to test the usefulness of data from three levelling campaigns for the construction of model of vertical movements and to develop a quasi-kinematic height network in the future. The main conclusions from the conducted analyses are: the limited trust regarding the data from the years 1953-1955 as well as the decision to withdraw these data from the process of determining the model of vertical crustal movements in Poland including the archive levelling data.

The collected levelling material was a majority status information of levelling data volume on the territory of Poland. The preliminary data analysis (identification of common benchmarks and calculation of loop disclosures) showed unfit data from 1926 to 1937 and the need for further identification of common benchmarks of 1953-155 and 1974-1982 campaigns. The prepared data was adjusted and the mutual assessment of residual distributions was performed for three adjustment variants. The performed adjustment did not show much convergence of vertical movement direction at the nodes of double and triple levelling. The statistical assessment using the box-plot showed a large disturbance in the observation residuals in the years 1953-1955 and 1974-1982. The posed hypothesis of mutual independence of residuals of triple levelling data proved to be correct.

The final QQ test confirmed that the data from the years 1953-1955 are biased with problems too significant to provide a reliable material to develop 
a model of vertical crustal movements on the territory of Poland using the levelling data from the years 1921937, 1953-1955, 1997 - 2003.

Research on incorporation of vertical movement determined from permanent satellite observations is planned in the future. Satellite leveling currently offers mm-level accuracy (Wielgosz et al., 2011), and according to the results presented in the paper by Kontny and Bogusz (2012), the correlation between vertical changes determined using precise levelling and GPS measurements is very small. This could result from the GPS antennas locus (mostly roofs of high buildings) as the Polish national GNSS network was designed rather for real-time services for geodesists, than for studies of local or regional kinematics. Therefore, a very detailed verification of GPS data has to be conducted before any kind of geodynamical interpretation. After verification it can serve as an additional reliable material for research on vertical crustal movements and it can support the development of the concept of quasi-kinematic height network on the territory of Poland.

The study on determination of mathematical algorithms which will allow incorporating the two types of data will begin in the near future. So will work regarding the concept of the height network taking into account the influence of the Earth's crust vertical movements.

\section{REFERENCES}

Ågren, J. and Svensson R.: 2007, Postglacial land uplift model and system definition for the New Swedish Height System RH 2000, Reports in Geodesy and Geographical Information Systems, LMV-Rapport 2007, 4 Gävle.

Benjamini, Y.: 1988, Opening the box of a boxplot. American Statistician, 42(4), 257-262.

Council of Ministers Regulation from 15 th october 2012 about national reference frame system Warsaw 14 November 2012, (in Polish).

Hollander, M. and Wolfe, D.: 1973, Nonparametric statistical methods. New York: John Wiley \& Sons, 185-194.

Kakkuri, J. and Vermeer, M.: 1985, The study of land uplift using the third precise levelling of Finland, Helsinki. Reports of the Finnish Geodetic Institute.

Kontny, B. and Bogusz, J.: 2012, Models of vertical movements of the Earth crust surface in the area of Poland derived from levelling and GNSS data, Acta Geodyn. Geomater., 9, No. 3 (167), 331-337.

Kowalczyk, K. and Rapiński, J.: 2011, New elaboration of gradient map of vertical crustal movements in the territory of Poland, Techn. SC., No 12, 245-254.

Kowalczyk, K., Bednarczyk, M. and Kowalczyk, A.: 2011, Relational database of four precise levelling campaigns in Poland ; 8th International Conference Environmental Engineering, 03/01, 1356-1361.
Kowalczyk, K., Rapiński, J. and Mróz, M.: 2010, Analysis of vertical movements modelling through various interpolation techniques, Acta Geodyn. Geomater., 7, No. 4 (160), 1-11.

Kowalczyk, K.: 2005, Determination of land uplift in the area of Poland, $6^{\mathrm{TH}}$ International Conference Environment, al Engineering, 1 and 2, 903-907.

Kowalczyk, K.: 2006a, New model of the vertical crustal movements in the area of Poland, Geodesy and Cartography, Vilnius, XXXII, No. 4, 83-87.

Kowalczyk, K.: 2006b, Modelling the vertical movements of the Earth's crust with the help of the collocation method, Reports on Geodesy, No 6. (76).

Kowalczyk, K.: 2006c, Estimation of vertical crustal movements model in Poland UWM Olsztyn. Ph. D. Thesis, (in Polish).

Kowalczyk, K.: 2008, Vertical crustal movements in Poland for instance any fragment three levellings network, 7th International Conference Environmental Engineering, 3, 1354-1358.

Sacher, M., Ihde, J., Liebsch, G. and Luthardt, J.: 2005, Steps on the Way to UELN05 and Enhancements of the Web-based Geodetic Information and Service System. Report on the Symposium of the IAG Subcommission for Europe (EUREF) in Vienna, June 1-4, 2005, In: Mitteilungen des Bundesamtes für Kartographie und Geodäsie, 8, 158-165, Frankfurt am Main 2006 .

Sacher, M., Liebsch, G., Ihde, J. and Mäkinen, J.: 2008, EVRF07 as Realization of the European Vertical Reference System Presented at the Symposium of the IAG Sub-commission for Europe (EUREF) in Brussels, June 18-21, 2008. Submitted to the proceedings.

Wielgosz, P., Paziewski, J. and Baryła, R.: 2011, On constraining zenith tropospheric delays in processing of local GPS networks with Bernese software. Survey Review 43, No 323, 472-483, DOI: 10.1179/003962611X13117748891877

Wilk, M.B. and Gnanadesikan, R.: 1968, Probability plotting methods for the analysis of data. Biometrika, 55(1), 1-17. 